\title{
Variability of soil moisture and its relationship with surface albedo and soil thermal diffusivity at Astronomical Observatory, Thiruvananthapuram, south Kerala
}

\author{
M S Roxy*, V B Sumithranand and G Renuka \\ Department of Physics, University of Kerala, Kariavattom, Thiruvananthapuram 695 581, India. \\ *e-mail: roxyms@gmail.com
}

\begin{abstract}
Continuous observation data collected over the year 2008 at Astronomical Observatory, Thiruvananthapuram in south Kerala $\left(76^{\circ} 59^{\prime} \mathrm{E}\right.$ longitude and $8^{\circ} 30^{\prime} \mathrm{N}$ latitude) are used to study the diurnal, monthly and seasonal soil moisture variations. The effect of rainfall on diurnal and seasonal soil moisture is discussed. We have investigated relationships of soil moisture with surface albedo and soil thermal diffusivity. The diurnal variation of surface albedo appears as a U-shaped curve on sunny days. Surface albedo decreases with the increase of solar elevation angle, and it tends to be a constant when solar elevation angle is greater than $40^{\circ}$. So the daily average surface albedo was calculated using the data when solar elevation angle is greater than $40^{\circ}$. The results indicate that the mean daily surface albedo decreases with increases in soil moisture content, showing a typical exponential relation between the surface albedo and the soil moisture. Soil thermal diffusivity increases firstly and then decreases with the increase of soil moisture.
\end{abstract}

\section{List of symbols}

$\begin{array}{ll}\text { Symbol } & \text { Description } \\ \alpha & \text { Surface albedo } \\ S_{u} & \text { Reflected solar radiation }\left(\mathrm{W} / \mathrm{m}^{2}\right) \\ S_{d} & \text { Total downward solar radiation } \\ & \left(\mathrm{W} / \mathrm{m}^{2}\right) \\ T & \text { Soil temperature }\left({ }^{\circ} \mathrm{C}\right) \\ k & \text { Soil thermal diffusivity }\left(\mathrm{m}^{2} \mathrm{~s}^{-1}\right) \\ t & \text { Time }(\mathrm{s}) \\ A & \text { Amplitude of the soil thermal wave } \\ & \text { at any depth }\left({ }^{\circ} \mathrm{C}\right) \\ A_{0} & \text { Amplitude of thermal wave at the } \\ & \text { Surface }\left({ }^{\circ} \mathrm{C}\right) \\ \omega & \text { Soil depth }(\mathrm{m}) \\ \theta & \text { Angular velocity of earth's } \\ \theta & \text { rotation }(\mathrm{rad} / \mathrm{s}) \\ W s & \text { Solar elevation angle }(\text { degree }) \\ \eta & \text { Average soil moisture }(\%)\end{array}$

\section{Introduction}

Soil moisture plays a very important role in the regional climate change (Elfatih 1998; Douville and Chauvin 2000; Timbal et al 2002; Koster et al 2004; Lakshmi et al 2004; Shi 2009). The variation of soil moisture changes the water supplied to plants by the soil and the moisture gradient between the land surface and the atmosphere, which control the water exchange between that land surface and the atmosphere (Song et al 2009). Additionally, as a low-pass filter of the land atmosphere system, soil moisture has a long memory (Pielke et al 1999; Wu et al 2002). The climatic anomalies persist because the memory of soil moisture is considerably longer than that of the atmospheric processes with which it interacts. Soil moisture can impact the exchange of energy and hydrological flux at the land surface boundary by changing the surface albedo and soil thermal properties.

Keywords. Soil moisture; rainfall; surface albedo; solar elevation angle; thermal diffusivity; atmospheric sciences; meteorology; geophysics. 
Surface albedo is an important factor in climate modelling and weather forecasting (Betts and Ball 1997). Albedo is the fraction of incident radiation that is reflected from the surface. In the physical climate system, albedo determines the radiation balance of the surface that affects the surface temperature and boundary-layer surface of the atmosphere. The earth's climate is very sensitive to the changes in the surface albedo. Error in the specification of soil albedo may cause biases in the computation of ground temperature and surface fluxes. Albedo directly controls the partitioning of radiation energy over land surfaces, which in turn, affects ecosystem physical, physiological, and biogeochemical processes such as energy balance, evapotranspiration, photosynthesis, and respiration (Wang et al 2002a, 2002b). It is important for the improvement of description of the land surface processes to investigate diurnal and seasonal changes of surface albedo.

Charney (1975) discussed the effect of surface albedo's change on the drought of Sahara Desert by using a general circulation model. He proposed that change of albedo is an important factor in maintaining or creating deserts and may be pertinent to drought conditions in the Sahel. He postulates a biogeophysical feedback mechanism in which lack of rainfall leading to a lack of vegetation results in a higher surface albedo; the consequent radiation deficiency requires sinking motion to maintain the heat balance and this leads to additional drying and thus to a continuation of desert conditions. The surface albedo has a negative effect on moisture flux convergences and rainfall, and desertification results generally in droughts by a positive feedback between land and atmosphere caused by high surface albedo. As expected from Charney's hypothesis on the maintenance of deserts, the use of more realistic albedos tends to transfer rainfall from regions of higher albedo to regions of lower albedo (Cunnington and Rowntree 1986).

According to Idso et al (1975), albedo is a linear function of water content of the uppermost layers of the soil. In recent years, some research has been done to challenge this study by indicating that albedo is an exponentially decreasing function of surface moisture content. Wang et al (2005) have analysed seasonal variation of the surface albedo in the Tibetan Plateau semi-desert surface and pointed out that the surface albedo decreases when the soil moisture content increases, which shows the typical exponential relation between surface albedo and soil moisture. They found that the soil thermal diffusivity first increases with soil moisture, then decreases slowly after reaching its maximum when soil moisture is about 0.25 (volume per volume).
Zhang and Huang (2004) investigated the diurnal change of the surface albedo in Dunhuang Gobi, the arid area in summer. The albedo of the dry soil surface is founded much larger than that of the wet soil surface just after precipitation. In another study, Liu et al (2008) analysed seasonal variations of the surface albedo in the semi-arid area of Tongyu over northeastern China. They noted that the surface albedo decreases exponentially with increases of soil moisture. The soil thermal diffusivity is found to increase with soil moisture and then to decrease after reaching to maximum at the soil moisture of 0.18 (volume per volume). Guan et al (2009) studied the seasonal changes in surface albedo and soil thermal properties and their relationships with soil moisture. The results indicate that surface albedo decreases when soil moisture content increases, showing a typical exponential relationship. The thermal diffusivity is found to increase as a power function of the soil moisture in the dry season. The study conducted by Gascoin et al (2009) clearly demonstrates that implementing the effect of soil moisture on bare soil albedo importantly influences the surface fluxes at the monthly and annual scale. They proposed that the effect of the bare soil albedo variability needs to be further investigated in other regions, especially in areas where the soil moisture exerts a strong influence on precipitation variability (e.g., the Sahel region, Koster et al 2004).

In this study, a series of one-year continuous measurements (from 1 January 2008 to 31 December 2008) from the automatic data acquisition system installed at Astronomical Observatory, Thiruvananthapuram is used to investigate the diurnal, monthly and seasonal variations of soil moisture. Effect of rainfall on diurnal and seasonal soil moisture has been studied. Diurnal and annual variations of surface albedo have been obtained. The changes of surface albedo with soil moisture and solar elevation angle have been discussed. Thermal characteristics of soil greatly influence the energy budget of the plant environment. Heat stored in a soil depends on its thermal characteristics effect, i.e., the evaporation that takes place at the surface. In view of this, the study of influence of soil moisture on thermal diffusivity is undertaken. The knowledge of the pattern of soil moisture distribution at various depths and its fluctuation in relation to rainfall is vital for studying the hydrological cycle. The information on the relationship between surface albedo and soil moisture is crucial to improve the performance of numerical weather and climate models. The values of the soil thermal diffusivity derived here can be used as input in land surface processes. 


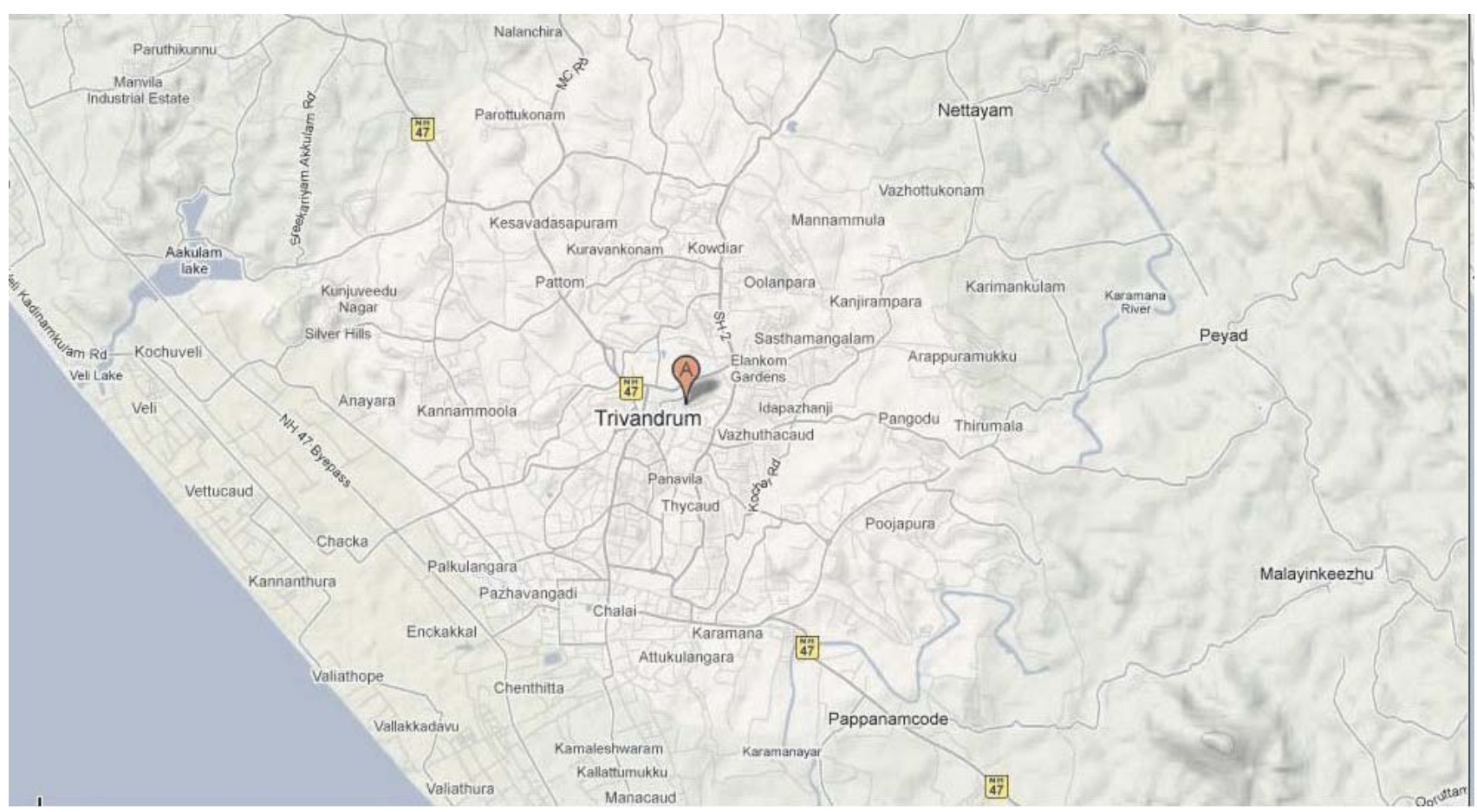

(a)



\section{Site and data}

The study was conducted at Astronomical Observatory $\left(76^{\circ} 59^{\prime} \mathrm{E}\right.$ longitude and $8^{\circ} 30^{\prime} \mathrm{N}$ latitude), University of Kerala, adjacent to India Meteorological Department, Thiruvananthapuram in south Kerala (figure 1a and $1 \mathrm{~b}$ ). It is situated at about $64.31 \mathrm{~m}$ above mean sea level and nearly $8.4 \mathrm{~km}$ inland from coast. The climate of Kerala is tropical maritime and monsoonal in character. Temperature and humidities are high throughout the year. Pressure gradients are weak. Rainfall is abundant
Figure 1. (a) An overall view of the location of the experimental site $\left(76^{\circ} 59^{\prime} \mathrm{E}\right.$ longitude and $8^{\circ} 30^{\prime} \mathrm{N}$ latitude). (b) Land use map of the location. Red colours indicate urban areas while the shades of green represent different forest types. The location is represented as a white dot for reference.

with rain for nearly ten months of the year. There is some rain even in the rest of the two months (Menon and Rajan 1989). Kerala is the land of monsoons. In fact the first burst of the south-west monsoon over the Indian subcontinent takes place over Kerala. The main rainy seasons in the state are south-west (SW) monsoon (June-September) and north-east (NE) monsoon (October and November). The pre-monsoon months (MarchMay) account for major thunderstorm activity in the state and winter months (December-February) are notable by minimum rainfall. 
Kerala comes under iso-hyperthermic temperature regime (Chacko and Renuka 2008) which means that annual soil temperature is $22^{\circ} \mathrm{C}$ or higher and mean soil temperature of June-August and December-February differ by less than $5^{\circ} \mathrm{C}$ at a depth of $50 \mathrm{~cm}$ or at lithic or paralithic contact whichever is shallower. The colour of the soil at the experimental site varies from dark brown to dark reddish brown as we go to the deeper layers. Correspondingly the soil texture varies from gravelly sandy loam to gravelly clay loam. The clay increase in sub-surface layers qualifies these soils to place under ultisols. The experimental site belongs to soils of laterite landscape developed under tropical climate with alternate wet and dry seasons.

Soil temperature at depths of 0.05 and $0.10 \mathrm{~m}$, soil moisture at depths of $0.05,0.10,0.20,0.30$ and $0.50 \mathrm{~m}$ and incident solar radiation and reflected solar radiation were recorded at one-hour interval using hydro-meteorological data acquisition system installed at the observational site. Unfortunately data for the month of April 2008 is missing due to technical reasons. The sensing element for soil temperature is $\mathrm{P}-\mathrm{N}$ junction semiconductor with fast response designed for continuous and long term measurements at soil depth. It is encased inside stainless steel cover filled with silicon for better thermal conductivity and also to withstand the high geostatic pressure and rough handling in the field. A principle based on soil impedance is employed to sense the soil moisture directly from soil depths. Here the sensor is excited with sinusoidal signals of a selected and fixed frequency for eliminating electrical polarization and hence to obtain long term consistency in performance. The sensor associated with its signal conditioning, processed with embedded software eliminates the inherent non-linearity in its performance (Sivadas 2007). The sensors installed at different depths from the soil surface measure soil temperature between 0 and $60^{\circ} \mathrm{C}$ and soil moisture between 0 and $50 \%$. The resolutions of soil temperature and moisture data are $0.1^{\circ} \mathrm{C}$ and $0.1 \%$ with accuracy of $\pm 0.2^{\circ} \mathrm{C}$ and $\pm 0.2 \%$ respectively. Both incidents and reflected solar radiation sensors are developed using wide spectrum photodiodes. The resolution of the solar radiation estimation sensors is $1 \mathrm{~W} / \mathrm{m}^{2}$ with an accuracy of $\pm 1 \mathrm{~W} / \mathrm{m}^{2}$. Analog-to-digital Converter (ADC) with 12 bits resolution, $1000 \mathrm{~KB}$ of non-volatile memory, built-in real time clock, suitable for single analogous channel for multiplexing up to 256 channels, RS232 port for feeding data to computer is used for data storage. Software supports downloading data to computer and display of data of all channels in real time. The instruments have been tested and calibrated at regular intervals by the manufacturers (Environmental
Measurements and Controls, Cochin) with the help of national calibrating agency (IMD, Pune). The data is compared with imported and good performance types available with Central Institute of Fisheries Technology (CIFT), Cochin and Rubber Research Institute of India (RRII), Kottayam. All the sensors have good linearity and sensitivity which is approved by the calibration certificate of IMD, Pune. The rainfall data for the year 2008 is collected from IMD, Thiruvananthapuram.

\section{Method}

Land surface albedo $(\alpha)$ can be calculated from measurements of the short wave radiation components as follows:

$$
\alpha=\frac{S_{u}}{S_{d}},
$$

where $S_{u}$ is the total upward solar radiation (reflected solar radiation) and $S_{d}$ is the total downward solar radiation reaching the surface. Surface albedo is generally influenced by soil colour, surface roughness, soil moisture, solar elevation angle, snow cover, and so on. Solar elevation angle and soil moisture are the two main factors which influence the albedo ( $\mathrm{Li}$ and $\mathrm{Hu} 2009$ ). To study the impact of soil moisture on surface albedo, it is necessary to first examine the influence of solar elevation angle on the surface albedo. To do this, day time hourly albedo is calculated using equation (1) for the year 2008. The solar elevation can be calculated from the longitude and latitude of the site, Julian day, and mean observational time (solar elevation angle is the complement angle of solar zenith angle). Surface albedo is a double variable function of solar elevation angle and soil moisture. Hence to accurately investigate the influence of the solar elevation angle on surface albedo, the impact of soil moisture is to be suppressed. The hourly datasets during rainy days are not used. Hence, those datasets with moisture content less than $20 \%$ are selected. In addition, sharp peaks in surface albedo are also removed.

The thermal diffusivity of soil is the ratio of its heat conductivity and its volumetric heat capacity. It is an important parameter for the determination of temperature distribution and heat flux in the soil. This parameter which contributes to the characterization of the soil microclimate, depends on moisture content and texture of the soil. Experimental determination of thermal diffusivity of soil is not easy in the field; hence it has been determined using the measured soil temperatures. The heating of the earth's surface by 
the sun during the day, followed by cooling during night, results in a diurnal temperature wave with a time period of 24 hours. The equation for conductive heat transfer in a one-dimensional isotropic medium (Kaushik et al 1965) is:

$$
\frac{\partial T}{\partial t}=k \frac{\partial^{2} T}{\partial z^{2}}
$$

where $T$ is the soil temperature, $k$ is the soil thermal diffusivity, $t$ the time and $z$ the depth. The thermal diffusivity can be estimated from measurements of amplitude decrement and phase difference of the temperature waves between various depths in the ground. The solution of equation (1) yields the amplitude $A$ of the temperature wave at any depth $z$ given by:

$$
A=A_{0} \exp \left[-\sqrt{\frac{\omega}{2 k}} z\right]
$$

where $A_{0}$ is the amplitude of the thermal wave at the surface and $\omega$ is the angular velocity of earth's rotation $\left(7.292 \times 10^{-5} \mathrm{rad} / \mathrm{s}\right)$. Thus it follows from equation (3) that the amplitude equation for calculating thermal diffusivity is given by:

$$
k=\frac{\omega}{2}\left[\frac{z}{\ln \left(A / A_{0}\right)}\right]^{2}
$$

\section{Results and discussion}

\subsection{Seasonal cycle of soil moisture}

The climate variations in different months affect the temperature and moisture content of the soil. In this study, the monthly average of the hourly soil moisture for one year is calculated for different depths. Figure 2 shows the seasonal variation of soil moisture at $5 \mathrm{~cm}, 10 \mathrm{~cm}, 20 \mathrm{~cm}, 30 \mathrm{~cm}$ and $50 \mathrm{~cm}$ depths for the period from January 2008 to December 2008. The variations in soil moisture at different depths are found to be almost constant. The moisture content is low during the dry season and it increases as the rainy season begins. To study the seasonal variations of soil moisture in relationship with the rainfall, seasonal mean of soil moisture and the corresponding total rainfall is plotted in figure 3. The seasonal average soil moisture content values in different soil layers were found to range between $16.16 \%$ and $25.94 \%$ during winter, $18.06 \%$ to $27.52 \%$ during pre-monsoon, $27.62 \%$ to $38.02 \%$ during SW monsoon and $27.10 \%$ to $36.75 \%$ during NE monsoon seasons, respectively. The corresponding total rainfall is $9.57 \mathrm{~cm}$, $43.11 \mathrm{~cm}, 71.66 \mathrm{~cm}$ and $60.25 \mathrm{~cm}$, respectively. It is found that variation in rainfall in different seasons causes the variation in soil moisture. In the rainy monsoon seasons (SW monsoon and NE monsoon), the soil is wetter than the dry seasons (winter and pre-monsoon). Even though the rainfall is minimum during winter, the soil possesses average moisture in between $16.16 \%$ to $25.94 \%$. Since the winter season follows rainy seasons, soil moisture conditions during winter themselves reflect past occurrence of rainfall.

The monthly averaged soil moisture is higher for deeper layer than the surface layer. This may be due to the rapid evaporation of soil moisture from the surface layer. The soil also supports water movement to the deeper layers. The presence of more moisture content at deeper levels was noticed while digging for installing the sensors. The moisture kept near the soil surface may start being transported down into the soil as well as into the atmosphere when the solar radiation hits the surface. The moisture content in the atmosphere and that in the soil are closely related to each other through the evaporation from the soil surface. The variation of water vapour content in the air adjacent to the soil surface was not available to investigate this relationship. To investigate how the available moisture at the surface is depleted, we selected 23 consecutive days (October 20 -November 11). Out of these 23 days, the first eight days (October 20-27) and the last three days (November 9-November 11) were rainy days. The days from October 28 to November 8 were non-rainy days. There were considerable amount of rainfall at the starting of the observational days. The total rainfall from October 20 to 27 are $56.44 \mathrm{~mm}, 36.1 \mathrm{~mm}, 67.6 \mathrm{~mm}, 23.6 \mathrm{~mm}$, $18.6 \mathrm{~mm}, 43.7 \mathrm{~mm}, 26.6 \mathrm{~mm}$ and $0.2 \mathrm{~mm}$, respectively. Figure 4 illustrates the drying cycle after the rainfall event. The rainfall reaches its minimum on November 8; it was recharged after the November 9th rainfall event. From figure, it is seen that towards the end of the non-rainy days, the surface layer become more and more dry. During the next rainy days from 9 to 11 November (with total rainfall $24.5 \mathrm{~mm}, 53.3 \mathrm{~mm}, 20 \mathrm{~mm}$ ), the moisture content in the upper layer increases significantly as seen in the figure.

\subsection{Diurnal variations of soil moisture}

To study the diurnal variations in soil moisture at different seasons, seasonal mean of diurnal soil moisture at different depths were calculated. Figure 5 shows the seasonal mean of diurnal soil 


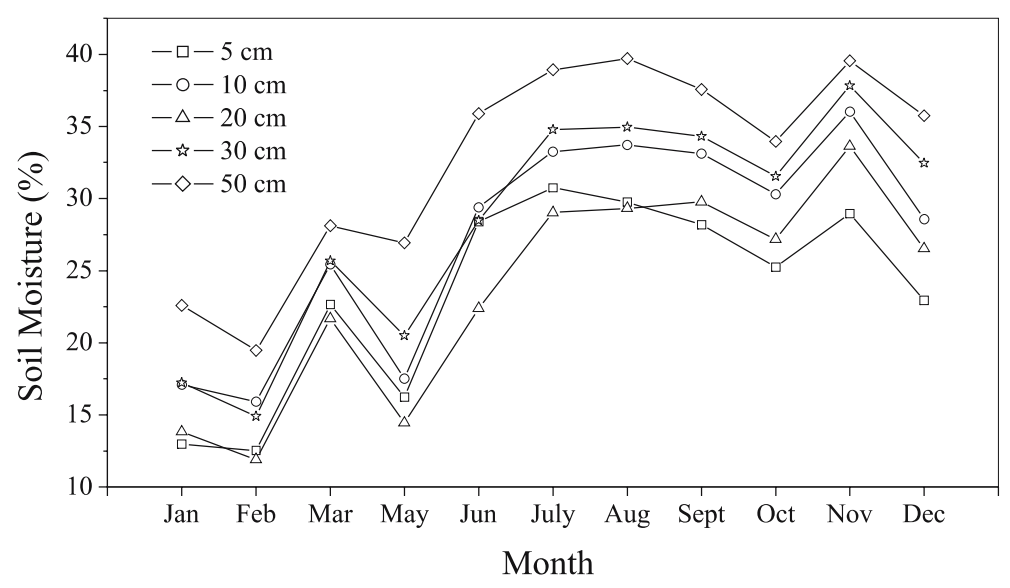

Figure 2. Monthly mean soil moisture.

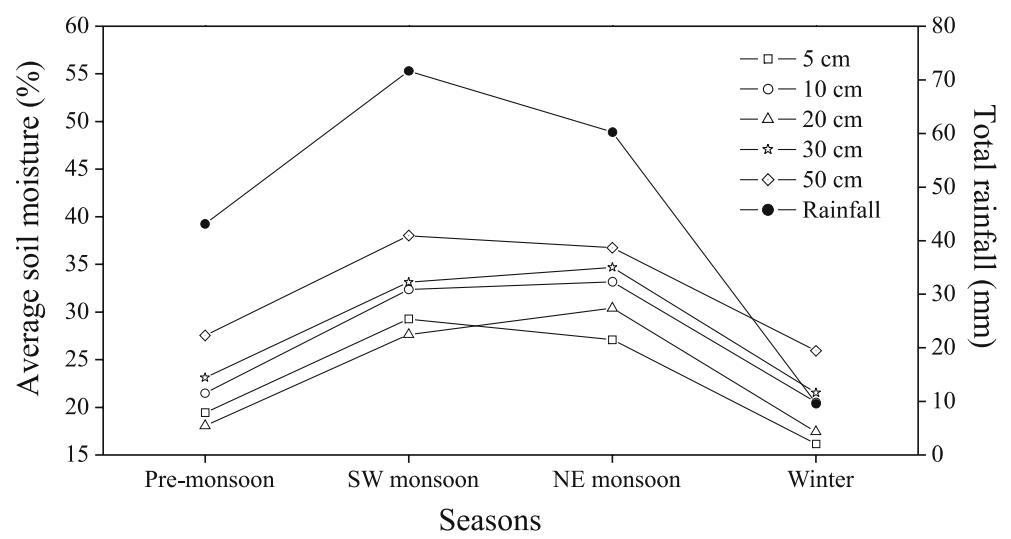

Figure 3. Seasonal variation of average soil moisture with total rainfall.

moisture variation in different seasons for different depths. Here, we find that soil moisture is different for the four seasons. Soil moisture content values were found to range between $17.45 \%$ and $28.09 \%, 16.21 \%$ to $27.19 \%, 26.76 \%$ to $38.32 \%$ and $25.98 \%$ to $38.32 \%$ during pre-monsoon, winter, SW monsoon and NE monsoon seasons, respectively. All the five layers depict distinctly lower soil moisture during pre-monsoon and winter and higher soil moisture during SW monsoon and NE monsoon. In all seasons, the amplitude of the seasonal mean soil moisture variations decreases with depth. The diurnal variations at 20,30 and $50 \mathrm{~cm}$ do not have obvious changes in contrast to the shallow layer. A similar variation in soil moisture is also reported by Guan et al (2009). The daily amplitude at $5 \mathrm{~cm}$ is greatest but is found to be too small. The soil moisture at $5 \mathrm{~cm}$ is not the maximum of all the depths. The diurnal variation reaches its minimum around 0800 LST and maximum around 1600 LST. We observed that soil water content varied greatly in the rainy season and less in the dry season. It is natural to suspect that this pattern might be greatly related to precipitation and evaporation.

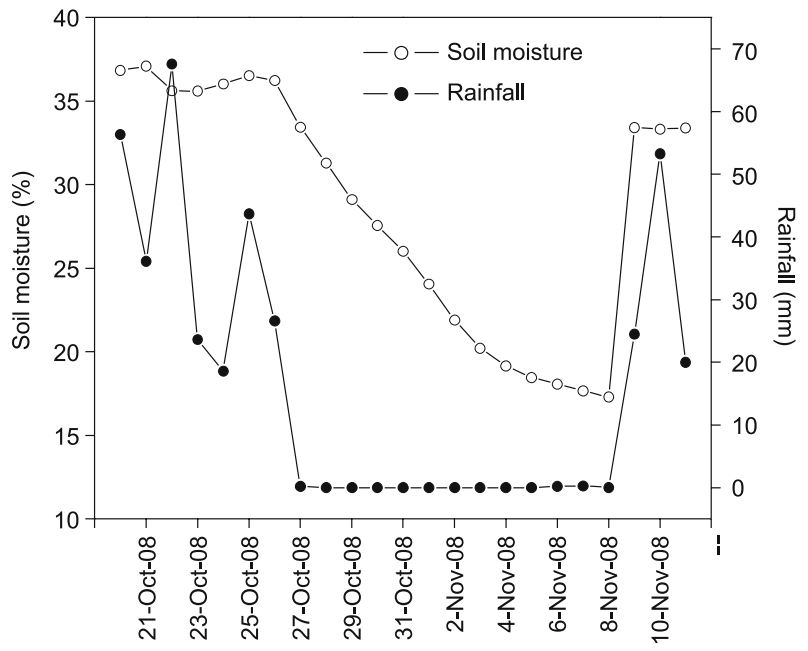

Figure 4. Day-by-day variations of soil moisture.

To demonstrate the influence of rainfall on the diurnal cycle of soil moisture, three consecutive rainy (October 20-22) and non-rainy (November 3-5) days are used. As evident from figure 6, during rain-free days, the diurnal variability is not strong. 

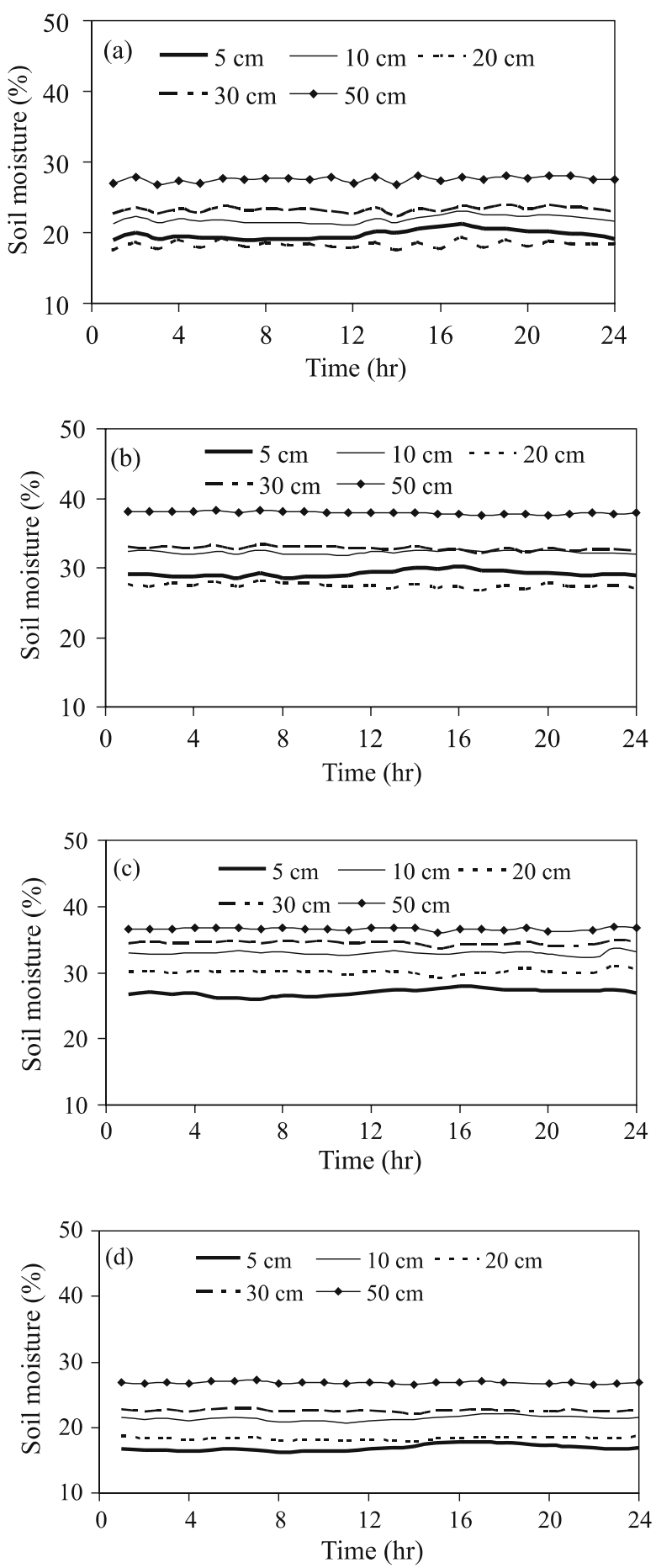

Figure 5. Seasonal mean of diurnal soil moisture variation for (a) pre-monsoon, (b) SW monsoon, (c) NE monsoon, and (d) winter.

On October 20, the soil moisture goes on increasing due to continuous rainfall. On October 21, based on rainfall observations recorded at the site, rainfall occurred after 1900 LST, causing a significant change in moisture content. On October 22 also, considerable rainfall occurred around 0500 LST and 1800 LST resulting in notable change in diurnal soil moisture. The moisture on rainy days is

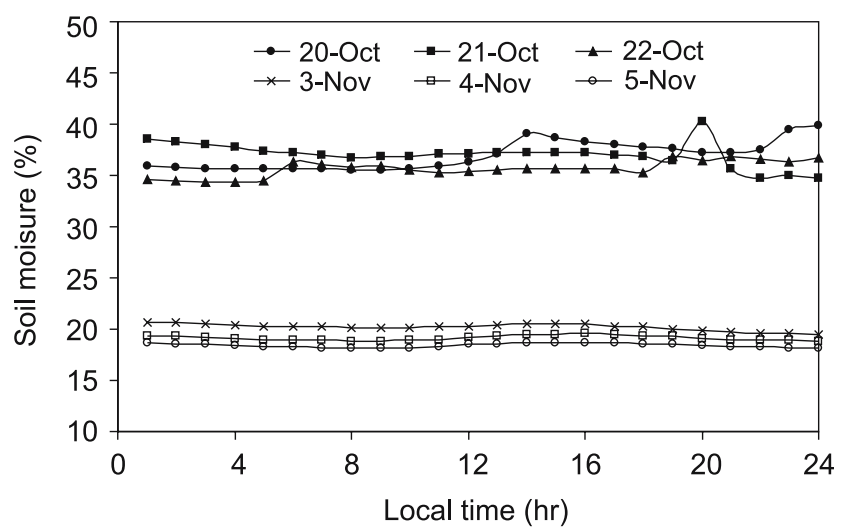

Figure 6. Diurnal variation of soil moisture on rainy and non-rainy days.

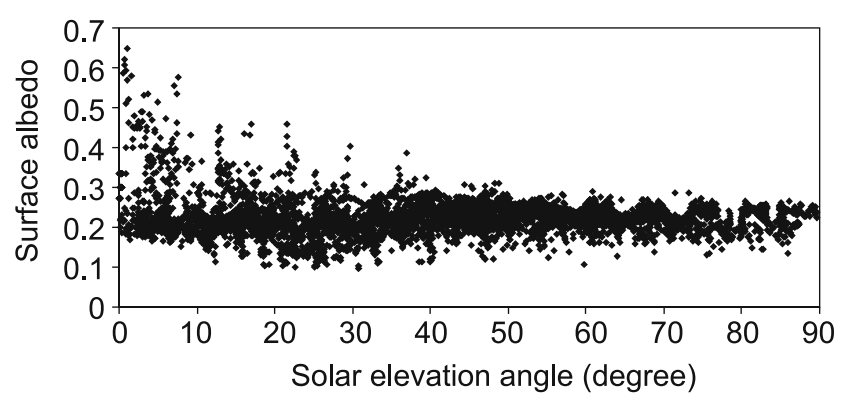

Figure 7. The influence of solar elevation angle on hourly surface albedo.

observed to be very high as compared to non-rainy days. Similar results were reported by Sun and Pinker (2004).

\subsection{Surface albedo and soil moisture}

We have selected the soil moisture data corresponding to the surface albedo data. We can see from figure 7 that solar elevation angle varies from $0^{\circ}$ to $90^{\circ}$. It is found that the influence of solar elevation angle on surface albedo is small enough to be omitted when the solar elevation angle varies from $40^{\circ}$ to $90^{\circ}$. The surface albedo tends to be a constant when the solar elevation angle is greater than $40^{\circ}$. In this work, the daily average albedo calculated from solar elevation angle larger than $40^{\circ}$ can be used to study its variation with soil moisture without introducing significant errors. Fitted surface albedo $(\alpha)$ as a function of solar elevation angle $(\theta)$ gives the following formula,

$$
\alpha=0.2221+0.1113 \exp \left(\frac{-\theta}{3.629}\right) .
$$

Similar relationship was obtained by Liu et al (2008).

Figure 8 shows the time series of the daily average surface albedo and daily average soil moisture 




Figure 8 . The time series of daily surface albedo and soil moisture for the year 2008 .

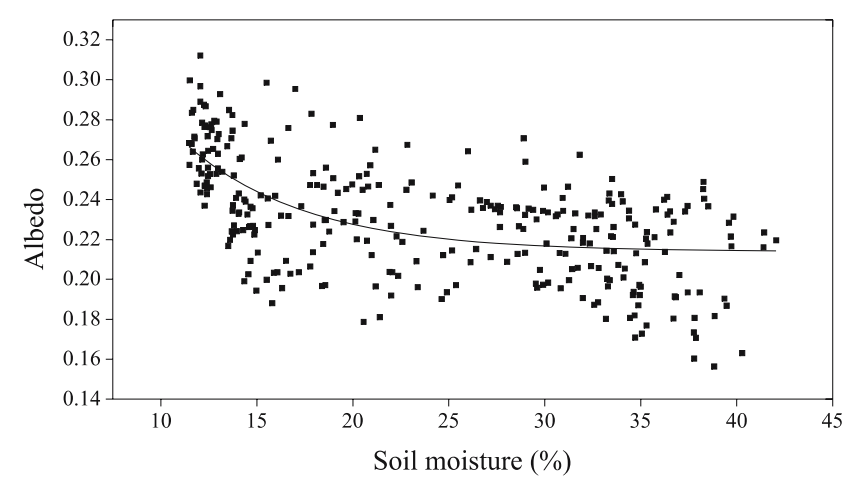

Figure 9. The change of daily average surface albedo with daily average soil moisture at $5 \mathrm{~cm}$.

content at $5 \mathrm{~cm}$ depth from 1 January 2008 to 31 December 2008. From the figure, it is seen that the surface albedo varies inversely with soil moisture. Daily mean surface albedo has obvious seasonal variation also, while it is small in SW monsoon and NE monsoon, and large in pre-monsoon and winter. During monsoon, each rainfall event corresponds to the decrease of the daily mean surface albedo because soil moisture increased after rainfall.

Figure 9 shows the relationship between daily soil moisture content at $5 \mathrm{~cm}$ depth and daily surface albedo. Here, daily average of the hourly day time surface albedo and soil moisture were taken. One can see that the albedo decreases with increasing soil moisture content, with the data fit by the following equation,

$$
\alpha=0.2106+0.1762 \exp \left(\frac{-W s}{9.321}\right),
$$

where $\alpha$ is the daily average surface albedo and $W s$ is the daily average soil moisture at $5 \mathrm{~cm}$. The value of $R^{2}$ is 0.3213 for the regression. Similar exponential relations have also been derived by Wang et al (2005), Liu et al (2008) and Guan et al (2009). Changes in soil moisture content change the absorbance and reflectance characteristics of the soil. Increase in soil moisture content

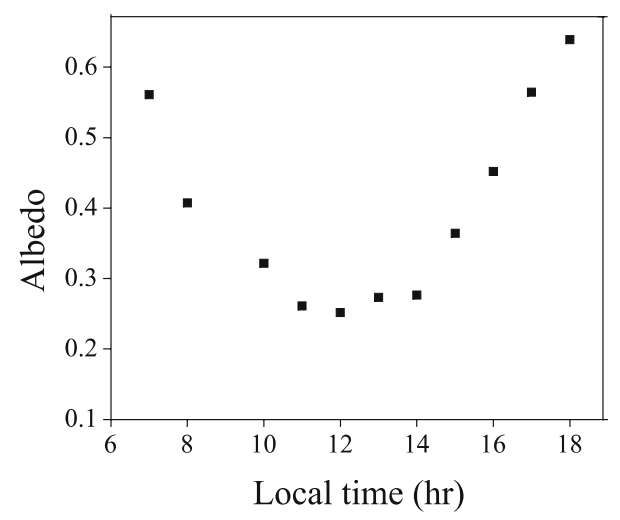

Figure 10. Diurnal variation of surface albedo on a clear day.

increases the portion of the incident solar radiation absorbed by the soil system. Soil moisture absorbs the incident radiation and decreases albedo.

The typical diurnal variation of the surface albedo on clear day looks like U-shaped curve, while it is low at noon, and is slightly higher in the morning and afternoon (figure 10). The lower the solar elevation angle, the larger the surface albedo becomes. With the increase of solar elevation angle, the surface albedo becomes small and changes very little. This is consistent with the results of Zhang et al (2002), Bao et al (2008) and Liu et al (2008). It is to be expected, if a strong relationship exists between surface albedo and solar elevation angle, that the diurnal distribution of albedo should be symmetrical about noon. But, the forenoon values of albedo are found as lower than the afternoon values for similar solar elevation angles. Solar heating would dry the soil during the day. The moisture withdrawal from the bare ground may be responsible for the higher afternoon albedo values which cause the asymmetry.

Estimation of clear sky albedo generally assumes that the albedo depends only on the solar elevation angle. The effects of frost, precipitation and evaporation can lead to some systematic diurnal variability resulting in an asymmetric diurnal cycle of albedo. Mayor et al (1996) pointed out that surface moisture has a significant effect and can change the albedo in the afternoon by $20 \%$ relative to its morning counter part. Such effects may need to be incorporated in mesoscale and even largescale models of atmospheric processes. Minnis et al (1997) pointed that surface moisture has a significant effect and can change the albedo by $10 \%$ at a given solar zenith angle between the morning and afternoon. The location chosen for the study may be influenced also by the sea breeze effects and it may cause an asymmetry in clear day albedo. As there were no simultaneous measurements of sea breeze data carried out at this station, the effect of 


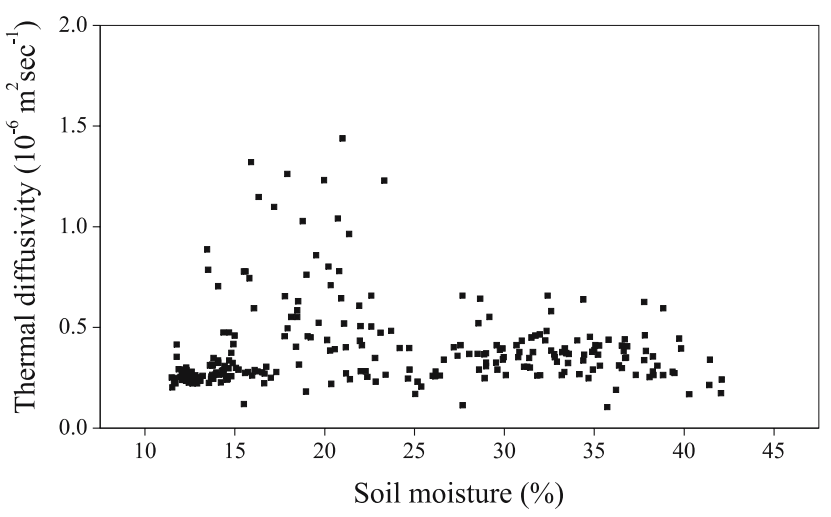

Figure 11. The changes of soil thermal diffusivity with soil moisture.

sea breeze on moisture and hence the albedo could not be included.

\subsection{Soil thermal diffusivity}

Soil thermal diffusivity for the year 2008 is calculated using amplitude equation (4). The dependence of soil thermal diffusivity on soil water content has a complex and nonlinear character (Arkhangel'skaya 2009). Figure 11 shows the variation of thermal diffusivity with soil moisture, where we can see that thermal diffusivity firstly increases with increasing soil moisture and then decreases after reaching its maximum at soil moisture of approximately $22 \%$. Water and air are the only soil constituent which vary considerably on a daily basis but since water has about 20 times the thermal conductivity of air, it is more influential on the soil thermal properties. Presence of water films at points of contact between particles not only improves the thermal contact but also replaces air in the soil pore space (Baver et al 1972; Hanks and Ashcroft 1986).

From the figure, one can see that the distribution of soil thermal diffusivity is scattered. The possible reason is that soil thermal diffusivity depends not only on soil moisture but also other factors like change in volumetric air and soil phase content. Padmanabhamurty et al (1998) examined how thermal diffusivity varies with different characteristics of soil, like moisture, texture, etc. They found that for a clay soil, average values of thermal diffusivity calculated by different methods for the sites Khanda and Arnej are $0.287 \times 10^{-6} \mathrm{~m}^{2} \mathrm{~s}^{-1}$ (volumetric moisture content, $\eta=0.248 \mathrm{~m}^{3} \mathrm{~m}^{-3}$ ) and $0.304 \times 10^{-6} \mathrm{~m}^{2} \mathrm{~s}^{-1} \quad\left(\eta=0.230 \mathrm{~m}^{3} \mathrm{~m}^{-3}\right)$, respectively. For the loamy sand soil at Derol and Anand, the values of thermal diffusivity are $0.677 \times 10^{-6} \mathrm{~m}^{2} \mathrm{~s}^{-1} \quad\left(\eta=0.133 \mathrm{~m}^{3} \mathrm{~m}^{-3}\right) \quad$ and $0.508 \times 10^{-6} \mathrm{~m}^{2} \mathrm{~s}^{-1} \quad\left(\eta=0.120 \mathrm{~m}^{3} \mathrm{~m}^{-3}\right)$, respectively. For the clay loam soil at Sanand, the thermal diffusivity value is $0.591 \times 10^{-6} \mathrm{~m}^{2} \mathrm{~s}^{-1}$ $\left(\eta=0.069 \mathrm{~m}^{3} \mathrm{~m}^{-3}\right)$.

In another study, Anandakumar et al (2001) investigated the thermal properties at two sites at Kalpakam, located on the south east coast of India. The soil composition at location 1 is a mixture of clay, sand and organic materials, whereas at location 2 , the clay content is dominant. They reported that the value of $k$ at location 2 shows a decreasing trend due to the gradual day by day drying up of the soil layer. The value obtained for the day corresponding to wet soil surface is more than two times larger than the dry days. Tessy Chacko and Renuka (2002) calculated the thermal diffusivity of laterite soil at Kariavattom of south Kerala. The average value of $k$ of the soil calculated by range method for a wet $\left(\eta=0.32 \mathrm{~m}^{3} \mathrm{~m}^{-3}\right)$ and dry day $\left(\eta=0.13 \mathrm{~m}^{3} \mathrm{~m}^{-3}\right)$ are $0.633 \times 10^{-6} \mathrm{~m}^{2} \mathrm{~s}^{-1}$ and $0.336 \times 10^{-6} \mathrm{~m}^{2} \mathrm{~s}^{-1}$ and by lag method are $0.668 \times 10^{-6} \mathrm{~m}^{2} \mathrm{~s}^{-1}$ and $0.307 \times 10^{-6} \mathrm{~m}^{2} \mathrm{~s}^{-1}$, respectively. All these results give a feeling about the difference in thermal diffusivities of wet and dry soil surfaces. Soil water content plays an important role in determining soil thermal properties, because the conduction through the soil is largely electrolytic, thus when the soil moisture increase, the thermal conductivity rise, because water is a good conductor. It is known that the thermal diffusivity is directly proportional to thermal conductivity. So when the moisture increases, the thermal diffusivity also increases up to some limited soil water content. The maximum thermal diffusivity occurs at medium moisture values due to the added effect of vapour phase movement of moisture and heat transfer (Lamba and Bhandari 1998). Oke (1978) suggested that adding soil moisture to a dry soil initially results in an increase in thermal diffusivity and it begins to decline when moisture content exceeds $20 \%$ by volume. Also, the organic matter does not transfer heat as readily as mineral soil and lowers the thermal diffusivity.

\section{Conclusions}

- Based on one year measurements (from 1 January 2008 to 31 December 2008) in a laterite landscape, variations of surface albedo and soil thermal diffusivity with soil moisture content have been investigated.

- The diurnal and seasonal variations of soil moisture is analysed for the year 2008. It is found that the soil moisture is low during the dry seasons and high during the rainy seasons.

- The surface albedo becomes smaller with the increase of the solar elevation angle. When the solar elevation angle is greater than $40^{\circ}$, 
the surface albedo changes very little and tends to be a constant.

- The surface albedo decreases when the moisture content increases, which shows the exponential relation between surface albedo and soil moisture (figure 9). The diurnal variation of surface albedo appears as a U-shaped curve on a sunny day (figure 10).

- The diurnal variation of surface albedo is not symmetrical about mid-day.

- A nonlinear dependency between soil moisture and soil thermal diffusivity was observed. The thermal diffusivity firstly increases with soil moisture, then decreases after reaching its maximum at the soil moisture of $22 \%$ (figure 11 ).

\section{Acknowledgements}

We thank the Director and Staff members of the India Meteorological Department, Thiruvananthapuram for providing data required for this work and Dr Matthew Simpson, Department of Marine, Earth and Atmospheric Sciences, North Carolina State University, USA for his support in obtaining the land use map of the site. The authors are grateful to the anonymous reviewers for their thorough reviews and helpful comments and suggestions.

\section{References}

Anandakumar K, Venkatesan R and Thara V Prabha 2001 Soil thermal properties at Kalpakkam in coastal south India; Proc. Indian Acad. Sci. (Earth Planet Sci.) 110(3) 239-245.

Arkhangel'skaya T A 2009 Parameterization and mathematical modeling of the dependence of soil thermal diffusivity on the water content; Eurasian Soil Science $\mathbf{4 2 ( 2 )}$ 162-172.

Bao Y, Lu S, Zhang Y, Meng X and Yang S 2008 Improvement of surface albedo simulations over arid regions; $A d v$. Atmos. Sci. 25(3) 481-488.

Baver L D, Gardner W H and Gardner N R 1972 Soil Physics, 4th edn. (New York: John Wiley and Sons).

Betts A K and Ball J H 1997 Albedo on the boreal forest; J. Geophys. Res. 102 2891-2899.

Chacko P Tessy and Renuka G 2008 Thermal diffusivity of soils in iso-hyperthermic temperature regime by harmonic analysis; Indian J. Radio Space Phys. 37 360-365.

Charney J G 1975 Dynamics of deserts and drought in the Sahel; Quart. J. Roy. Meteor. Soc. 101(428) 193-202.

Cunnington W M and Rowntree P R 1986 Simulations of Saharan atmosphere - dependence on moisture and albedo; Quart. J. Roy. Meteor. Soc. 112 971-999.

Douville H and Chauvin F 2000 Relevance of soil moisture for seasonal climate predictions: A preliminary study; Clim. Dyn. 16 719-736.

Elfatih A B Eltahir 1998 A soil moisture-rainfall feedback mechanism 1. Theory and Observations; Water Resour. Res. 34(4) 765-776.
Gascoin S, Ducharne A, Ribstein P, Lejaeune Y and Wagnon 2009 Dependence of bare soil albedo on soil moisture on the moraine of the Zongo glacier (Bolivia): Implications for land surface modeling; Geophys. Res. Lett. 36 L02405.

Guan X D, Huang J P, Guo N, Bi J R and Wang G 2009 Variability of soil moisture and its relationship with surface albedo and soil thermal parameters over the Loess Plateau; Adv. Atmos. Sci. 26(4) 692-700.

Hanks R J and Ashcroft G L 1986 Applied Soil Physics (Berlin: Springer-Verlag).

Idso S B, Jackson R D, Reginato R J, Kimball B A and Nakayama F S 1975 The dependence of bare soil albedo on soil water content; J. Appl. Meteorol. 14 109-113.

Kaushik S B, Sharma G S and Mokhashi B G 1965 Preliminary studies on subsoil temperatures at Jodhpur; Def. Sci. J. 15(1) 30-35.

Koster R D et al 2004 Regions of strong coupling between soil moisture and precipitation; Science $\mathbf{3 0 5}$ 1138-1141.

Lakshmi V, Piechota T, Narayan U and Tang C 2004 Soil moisture as an indicator of weather extremes; Geophys. Res. Lett. 31 L11401.

Lamba B S and Bhandari S 1998 Some aspects of thermal diffusivity for various soil layers in different harmonics; Mausam 49(2) 255-258.

Li Y and Hu Z 2009 A study on parameterization of surface albedo over grassland surface in the northern Tibetan Plateau; Adv. Atmos. Sci. 26(1) 161-168.

Liu H Z, Wang B M and Fu C B 2008 Relationships between surface albedo, soil thermal parameters and soil moisture in the semi-arid area of Tongyu, Northeastern China; Adv. Atmos. Sci. 25(5) 757-764.

Mayor S, Smith W L Jr, Nguyen L, Alberta T A, Minnis P, Whitlock C H and Schuster G L 1996 Asymmetry in the diurnal variation of surface albedo; Technical Report: NASA-96-igars-sm.

Menon P A and Rajan C K 1989 Climate of Kerala (Cochin: Classic Publ.).

Minnis P, Mayor S, Smith W L Jr and Young D F 1997 Asymmetry in the diurnal variation of surface albedo; IEEE Trans. Geos. Remote Sens. 35(4) 879-891.

Oke T R 1978 Boundary Layer Climates (New York: John Wiley).

Padmanabhamurty B, Amaralingeswara Rao K and Mukherjee R 1998 A preliminary analysis of soil temperature at five different sites under land surface processes experiment in the Sabarmati river basin; Indian J. Radio Space Phys. 27 199-206.

Pielke R A, Liston G E, Eastman J E and Lu L X 1999 Seasonal weather prediction as an initial value problem; J. Geophys. Res. 104 19,463-19,479.

Shi X 2009 Initial soil moisture effects on the climate in China - a regional climate model study; J. Ocean Univ. China (Oceanic and Coastal Sea Research) 8 $111-120$.

Sivadas T K 2007 Sensors and measurement systems for environmental, marine, fisheries and agricultural applications (Cochin: Central Institute of Fisheries Technology).

Song Y M, Guo W and Zhang Y 2009 Numerical study of impacts of soil moisture on the diurnal and seasonal cycles of sensible/latent heat fluxes over semi-arid region; Adv. Atmos. Sci. 26(2) 319-326.

Sun D L and Pinker R T 2004 Case study of soil moisture effect on land surface temperature retrieval; IEEE Trans. Geos. Remote Sens. Lett. 1 127-130.

Timbal B, Power S, Colman R, Viviand J and Lirola S 2002 Does soil moisture influence climate variability and predictability over Australia? J. Climate 15 1230-1238. 
Tessy Chacko P and Renuka G 2002 Temperature mapping, thermal diffusivity and subsoil heat flux at Kariavattom of Kerala; Proc. Indian Acad. Sci. (Earth Planet Sci.) 111(1) 79-85.

Wang K C, Wang P C, Liu J M, Sparrow M, Haginoya S and Zhou X J 2005 Variation of surface albedo and soil thermal parameters with soil moisture content at a semidesert site on the western Tibetan Plateau; Bound.-Layer Meteorol. 116 117-129.

Wang S, Grant R F, Verseghy D L and Black T A 2002a Modeling carbon-coupled energy and water dynamics of a boreal aspen forest in a general circulation model land surface scheme; Int. J. Climatol. 22 1249-1265.
Wang S, Grant R F, Verseghy D L and Black T A 2002b Modeling carbon dynamics of boreal forest ecosystems using the Canadian land surface scheme; Climatic Change 55 451-477.

Wu W R, Geller M A and Dickinson R E 2002 The response of soil moisture to long-term variability of precipitation; J. Hydrometeor. 3 604-613.

Zhang Q, Cao X and Wei G 2002 Observation and study of land surface parameters over Gobi in typical arid region; Adv. Atmos. Sci. 19(1) 121-134.

Zhang Q and Huang R H 2004 Parameters of land-surface processes for Gobi in North-west China; Bound.-Layer Meteorol. 110 471-478. 